Pesq. Vet. Bras. 34(Supl.1):79-86, dezembro 2014 DOI: 10.1590/S0100-736X2014001300015

\title{
Perfil bioquímico, inclusive proteinograma, do soro lácteo de búfalas primíparas e pluríparas sadias ao longo da lactação ${ }^{1}$
}

\author{
Lucas J.L. Pizauro ${ }^{2 *}$, Daniela G. da Silva², André M. Santana², Stella M.A. Morais ${ }^{2}$, \\ Natália C. Benincasa ${ }^{2}$ e José J. Fagliari ${ }^{2}$
}

\begin{abstract}
Pizauro L.J.L., Silva D.G., Santana A.M., Morais S.M.A., Benincasa N.C. \& Fagliari J.J. 2014. [Biochemical profile, including protein concentration, of whey from healthy primiparous and pluriparous buffaloes during lactation.] Perfil bioquímico, inclusive proteinograma, do soro lácteo de búfalas primíparas e pluríparas sadias ao longo da lactação. Pesquisa Veterinária Brasileira 34(Supl.1):79-86. Departamento de Clínica e Cirurgia Veterinária, Faculdade de Ciências Agrárias e Veterinárias, Universidade Estadual Paulista "Júlio de Mesquita Filho", Via de Acesso Prof. Paulo Donato Castellane s/n, Jaboticabal, SP 14884-900, Brazil. E-mail: lucaspizauro@yahoo.com.br

To evaluate the biochemical profile and protein concentration of whey from milk samples of healthy Murrah primiparous and pluriparous buffaloes, 30 female buffaloes were analyzed during a complete lactation. The animals were divided into three groups: G1 = 10 primiparous buffaloes, G2 $=10$ pluriparous buffaloes with 2-3 lactations and G3 $=10$ pluriparous buffaloes with $>3$ lactations. The lactation period was divided into: early stage (I: 1-3 months of lactation), intermediate stage (T: 4-6 months of lactation) and final stage (F: 7-9 months of lactation). Before milk sampling, physical examination of the mammary gland, strip cup test and California Mastitis Test (CMT) were performed. After mammary quarters asepsis, $20 \mathrm{~mL}$ of milk were collected monthly from each mammary quarter, during a complete lactation, in sterilized plastic bottles without preservative, in order to perform microbiological isolation, biochemical profile and protein electrophoresis in sodium dodecyl sulfate polyacrylamide gel electrophoresis (SDS-PAGE), and 30mL of milk from each mammary quarter were collect, in sterilized plastic bottles containing preservative bronopol to perform the somatic cell count (SCC). A total of 1,042 milk samples were collected from the experimental groups during lactation, of which 923 samples showed negative reaction to CMT and negative microbiological isolation and were selected to biochemical profile analysis and protein electrophoresis in SDS-PAGE. There were influence of parity order and stage of lactation in biochemical profile and protein concentration of healthy Murrah buffaloes' whey. Primiparous buffaloes (G1) showed higher gamma-glutamyltransferase (GGT: 2,346 U/L), alkaline phosphatase (ALP: $181 \mathrm{U} / \mathrm{L}$ ), phosphorus (P; $56.6 \mathrm{mg} / \mathrm{dL})$, potassium $(\mathrm{K} ; 32.0 \mathrm{mg} / \mathrm{dL})$ and $\alpha$-lactalbumin $(458 \mathrm{mg} / \mathrm{dL})$. Buffaloes with 2-3 lactations (G2) showed higher SCC $(70,700$ cells $/ \mathrm{mL})$ and higher concentrations of total protein $(1.55 \mathrm{~g} / \mathrm{dL})$, albumin $(100 \mathrm{mg} / \mathrm{dL})$, magnesium $(\mathrm{Mg} ; 8.80 \mathrm{mg} / \mathrm{dL})$, chlorides $(\mathrm{Cl} ; 176 \mathrm{mg} / \mathrm{dL})$, iron $(\mathrm{Fe} ; 10.7 \mu \mathrm{g} / \mathrm{dL})$, sodium $(\mathrm{Na} ; 178 \mathrm{mMol} / \mathrm{L})$ and lactoferrin $(59.5 \mathrm{mg} /$ $\mathrm{dL}$ ). Bufalloes with $>3$ lactations (G3) showed higher concentrations of total calcium (Ca; $41.8 \mathrm{mg} / \mathrm{dL}$ ), ionized calcium (iCa; $2.92 \mathrm{mMol} / \mathrm{L}$ ), immunoglobulin A (IgA; $1.32 \mathrm{mg} / \mathrm{dL}$ ), serum albumin $(99.1 \mathrm{mg} / \mathrm{dL})$, immunoglobulin $\mathrm{G}$ (IgG; $49.7 \mathrm{mg} / \mathrm{dL})$ and $\beta$-lactoglobulin $(1,068 \mathrm{mg} / \mathrm{dL})$. During lactation it was observed increase in SCC, GGT, ALP, total protein, albumin, $\mathrm{P}, \mathrm{Mg}, \mathrm{Cl}, \mathrm{Na}$, lactoferrin, serum albumin, IgG and $\alpha$-lactalbumin, as well as decrease in concentrations of $\mathrm{Ca}, \mathrm{Fe}, \mathrm{iCa}, \mathrm{K}, \mathrm{IgA}$ and $\beta$-lactoglobulin in buffaloes' whey. The
\end{abstract}

${ }^{1}$ Recebido em 16 de setembro de 2014.

Aceito para publicação em 6 de janeiro de 2015.

${ }^{2}$ Departamento de Clínica e Cirurgia Veterinária, Faculdade de Ciências Agrá- rias e Veterinárias (FCAV), Universidade Estadual Paulista "Júlio de Mesquita Filho" (Unesp), Via de Acesso Prof. Paulo Donato Castellane s/n, Jaboticabal, SP 14884-900, Brasil. *Autor para correspondência: lucaspizauro@yahoo.com.br 
results may be used as reference for buffaloes and to support diagnosis and prognosis of diseases common to lactation periods.

INDEX TERMS: Bubalus bubalis, mammary gland, somatic cell count (SSC), stage of lactation, SDS-PAGE.

RESUMO.- Para avaliar o perfil bioquímico, inclusive proteínas, do soro lácteo de búfalas Murrah primíparas e pluríparas sadias foram analisadas amostras de leite de 30 fêmeas bubalinas durante uma lactação completa. Os animais foram distribuídos em três grupos: G1 - 10 búfalas primíparas, G2 - 10 búfalas pluríparas com duas a três lactações e G3 - 10 búfalas pluríparas com mais de três lactações. 0 período de lactação foi dividido em: fase inicial (I: primeiro ao terceiro mês de lactação), fase intermediária (T: quarto ao sexto mês de lactação) e fase final (F: sétimo ao nono mês de lactação). Antes da colheita das amostras de leite foram realizados o exame físico da glândula mamária, o teste da caneca de fundo escuro e o California Mastitis Test (CMT). Após a assepsia dos quartos mamários, foram colhidas mensalmente, durante uma lactação completa, amostras de $20 \mathrm{~mL}$ de leite de cada quarto mamário, em frascos plásticos esterilizados e sem conservante, para a realização do isolamento microbiológico, determinação do perfil bioquímico e fracionamento proteico por meio de eletroforese em gel de poliacrilamida contendo dodecil sulfato de sódio (SDS-PAGE), e amostras de $30 \mathrm{~mL}$ de leite de cada quarto mamário, em frascos plásticos esterilizados contendo conservante bronopol, para contagem de células somáticas (CCS). Das 1.042 amostras de leite colhidas dos três grupos experimentais durante a lactação, 923 amostras de leite apresentaram reação negativa ao CMT e isolamento microbiológico negativo e foram selecionadas para as análises do perfil bioquímico e fracionamento proteico em SDS-PAGE. Notou-se influência da ordem de parto e da fase da lactação no perfil bioquímico e no proteinograma do soro lácteo de búfalas da raça Murrah sadias. As búfalas primíparas (G1) apresentaram maior atividade das enzimas gamaglutamiltransferase (GGT: 2.346U/L) e fosfatase alcalina (ALP: 181U/L) e maiores concentrações de fósforo (P: 56,6mg/ $\mathrm{dL}$ ), potássio (K: 32,0mg/dL) e $\alpha$-lactoalbumina (458mg/ dL). As fêmeas com duas a três lactações (G2) apresentaram maior CCS (70.700 células/mL) e maiores concentrações de proteína total $(1,55 \mathrm{~g} / \mathrm{dL})$, albumina $(100 \mathrm{mg} / \mathrm{dL})$, magnésio (Mg: 8,80mg/dL), cloretos (Cl: $176 \mathrm{mg} / \mathrm{dL}$ ), ferro (Fe: $10,7 \mu \mathrm{g} / \mathrm{dL}$ ), sódio (Na: $178 \mathrm{mMol} / \mathrm{L}$ ) e lactoferrina $(59,5 \mathrm{mg} / \mathrm{dL})$. As fêmeas com mais de três lactações (G3) apresentaram maiores concentrações de cálcio total (Ca: 41,8mg/dL), cálcio ionizado (Cai: 2,92mMol/L), imunoglobulina A (IgA: 1,32mg/dL), albumina sérica $(99,1 \mathrm{mg}$ / $\mathrm{dL}$ ), imunoglobulina G (IgG: 49,7mg/dL) e $\beta$-lactoglobulina (1.068mg/dL). Durante a lactação foi observado aumento da CCS, aumento das atividades das enzimas GGT e ALP, aumento das concentrações de proteína total, albumina, $\mathrm{P}, \mathrm{Mg}$, $\mathrm{Cl}, \mathrm{Na}$, lactoferrina, albumina sérica, IgG, $\alpha$-lactoalbumina e redução das concentrações de Ca, Fe, Cai, K, IgA e $\beta$-lactoglobulina no soro lácteo das búfalas. Os resultados obtidos podem ser utilizados como referências para a espécie bubalina e auxiliar no diagnóstico e no prognóstico de doenças de ocorrência comum na fase de lactação.
TERMOS DE INDEXAC̄̃̃: Bubalus bubalis, glândula mamária, contagem de células somáticas (CCS), estágio da lactação, SDS-PAGE.

\section{INTRODUÇÃO}

A bubalinocultura tem cada vez mais se destacado no cenário nacional, passando a ser uma opção economicamente rentável e deixando de ser apenas uma alternativa para a ocupação de terras impróprias para a criação de bovinos (Silva et al. 2013). Segundo dados do IBGE (2014), em 2013 a população de búfalos no país era de 1,33 milhão de animais, sendo que a região Sudeste apresentou um aumento de $4,3 \%$ do rebanho relativamente a 2012. 0 maior interesse pela criação de bubalinos deve-se ao fato da búfala produzir leite com características peculiares, com teor de sólidos que supera consideravelmente o do leite de vaca. Para a indústria de derivados lácteos o aproveitamento do leite bubalino é maior, com rendimento $40 \%$ superior ao do leite bovino (Andrade et al. 2011).

0 interesse por conhecimentos relacionados aos aspectos clínicos da glândula mamária e da composição do leite de búfalas tem aumentado devido, principalmente, à escassez de informações e ao fato de os bubalinos, assim como os bovinos, serem susceptíveis à mastite que, sabidamente, é causa relevante de redução da produção de leite e de alterações na qualidade do leite (Langoni et al. 2001). Nesse sentido, o fracionamento eletroforético das proteínas da secreção láctea tem sido utilizado para avaliar a função da glândula mamária de ruminantes, uma vez que as doenças inflamatórias podem estimular a produção, tanto no soro sanguíneo quanto no soro lácteo, de proteínas de fase aguda (Ceciliani et al. 2012). Adicionalmente, a avaliação do perfil bioquímico do soro lácteo, principalmente enzimas e minerais, mostrou ser um procedimento útil tanto para a avaliação da glândula mamária quanto para a avaliação da transferência de imunidade passiva aos neonatos (Martins Filho 2006, Baroza 2007, Rocha et al. 2014). A determinação de componentes bioquímicos do soro lácteo, em especial das proteínas de fase aguda, além de indicar a presença de doença inflamatória ativa, pode ainda auxiliar no prognóstico e/ou no monitoramento da resposta do paciente à terapia (Ganheim et al. 2007).

Dentre os fatores que provocam alterações na composição do leite merecem destaque não somente aqueles decorrentes das mastites, mas também os fatores relacionados à idade dos animais, raça, fase da lactação, condições climáticas e dieta dos animais (Patel et al. 1993). Portanto, é de fundamental importância o conhecimento das características e da composição do leite bubalino para o estabelecimento de valores de normalidade auxiliares no diagnóstico clínico e no desenvolvimento e aplicação de técnicas mais avançadas de prevenção e controle das infecções intramamárias nesta espécie (Bastos \& Birgel 2011). Assim, o estudo teve como objetivo avaliar o perfil bioquímico, inclusive 
proteínas e suas frações, do soro lácteo de búfalas Murrah primíparas e pluríparas sadias durante uma lactação completa.

\section{MATERIAL E MÉTODOS}

Foram avaliadas amostras de leite de 30 búfalas pertencentes a uma propriedade rural localizada no município de Analândia, Estado de São Paulo, durante uma lactação completa. As búfalas apresentavam produção média diária de $6 \mathrm{~kg}$ de leite/animal e eram criadas em sistema semiextensivo com dieta à base de volumoso e polpa cítrica suplementar. Estes animais eram ordenhados uma vez ao dia, pela manhã, utilizando-se ordenhadeira mecânica.

As búfalas foram distribuídas em três grupos: G1=10 fêmeas de primeira lactação, G2=10 fêmeas com duas ou três lactações e G3=10 fêmeas com mais de três lactações. 0 período de lactação foi dividido em: fase inicial (I: primeiro ao terceiro mês de lactação), fase intermediária (T: quarto ao sexto mês de lactação) e fase final (F: sétimo ao nono mês de lactação). Após a inspeção e palpação da glândula mamária (Radostits et al. 2007) foram realizadas a prova da caneca telada de fundo escuro e o California Mastitis Test-CMT (Schalm \& Noorlander 1957). Antes da obtenção das amostras de leite realizou-se assepsia dos quartos mamários com algodão embebido em álcool 70\%. Foram colhidas, mensalmente, durante uma lactação completa, amostras de $20 \mathrm{~mL}$ de leite de cada quarto mamário, em frascos esterilizados e sem conservante, para a realização do isolamento microbiológico, determinação do perfil bioquímico e fracionamento proteico em SDS-PAGE, e amostras de $30 \mathrm{~mL}$ de leite de cada quarto mamário, em frascos plásticos esterilizados contendo conservante bronopol, para contagem de células somáticas (CCS). Após a colheita, todas as amostras foram acondicionadas e transportadas em caixas isotérmicas, com gelo, até o laboratório.

Para o exame microbiológico, uma alíquota de $10 \mathrm{uL}$ de cada amostra de leite foi semeada em ágar sangue ovino desfibrinado $5 \%$ e ágar MacConkey, mantida a $37^{\circ} \mathrm{C}$, em condição de aerobiose, com leituras diárias durante 72 horas. Simultaneamente, as amostras de leite foram cultivadas em meio Sabouraud-dextrose, mantidas a $37^{\circ} \mathrm{C}$, para o isolamento de fungos (Quinn et al. 2005).

A contagem de células somáticas foi realizada em contador automático (Somacount 300, Bentley Instruments Incorporated, Minnesotta, USA), pelo método de citometria de fluxo.

O soro lácteo foi obtido após coagulação do leite pela adição de renina (Coalho Estrella, Chr. Hansen Brasil Ind. e Com. Ltda, Valinhos, São Paulo, Brasil), utilizando a técnica recomendada por Sant'Ana \& Birgel (2003). Após a adição de renina as amostras foram colocadas em banho-maria a $37^{\circ} \mathrm{C}$ durante 20 minutos e em seguida foram centrifugadas durante 20 minutos a $4.500 \mathrm{xg}$ a $4^{\circ} \mathrm{C}$.

Para avaliação do perfil bioquímico do soro lácteo foram determinadas as atividades das enzimas gamaglutamiltransferase (método de Szasz modificado) e fosfatase alcalina (método de Bowers e McComb modificado), bem como as concentrações de proteína total (método do biureto), albumina (método do verde de bromocresol), cálcio total (método de CPC), fósforo (método de Daly e Ertinghausen modificado), magnésio (método Labtest), cloretos (método Labtest) e ferro (método de Goodwin modificado), utilizando-se conjunto de reagentes comerciais (Labtest, Labtest Diagnóstica, Lagoa Santa, MG, Brasil). As leituras das amostras foram realizadas em espectrofotômetro semiautomático (Labquest, Labtest Diagnóstica, Lagoa Santa, MG, Brasil), com luz de comprimento de onda apropriado para cada teste. Adicionalmente foram determinados os teores de cálcio ionizado, sódio e potássio, pelo método de íons seletivos, em analisador automático (9180 Electrolyte Analyzer, Roche Diagnostics, Mannheim, Germany).
O fracionamento proteico do soro lácteo foi realizado mediante eletroforese em gel de poliacrilamida contendo dodecil sulfato de sódio (SDS-PAGE), segundo técnica descrita por Laemmli (1970). Após o fracionamento, o gel foi corado durante $10 \mathrm{minu}-$ tos com azul de coomassie brilhante $0,25 \%$ e, posteriormente, descorado em solução de ácido acético 7\% para retirar o excesso de corante, até que as frações proteicas se apresentassem nítidas. As concentrações das proteínas foram determinadas em densitômetro computadorizado (CS-9301 PC, Shimadzu Corporation, Tokyo, Japan). Como referência foi utilizada solução marcadora com diferentes pesos moleculares, além das proteínas purificadas IgG, haptoglobina, transferrina, ceruloplasmina, $\alpha_{1}$-antitripsina e lactoglobulina (Sigma, St Louis, MO, USA).

Os parâmetros avaliados foram submetidos à análise de variância (ANOVA) e ao teste de Tukey para comparação entre pares de médias (Triola 2008), ao nível de significância de 5\%, com auxílio do programa estatístico Statistical Analysis System (SAS - Versão 9.1).

\section{RESULTADOS E DISCUSSÃO}

Das 1.042 amostras de leite colhidas das búfalas dos três grupos experimentais durante uma lactação completa, 923 amostras de leite apresentaram reação negativa ao CMT e isolamento microbiológico negativo e foram selecionadas para a análise do perfil bioquímico e fracionamento proteico do soro lácteo por SDS-PAGE. Notou-se diferenças na contagem de células somáticas e no perfil bioquímico e proteinograma do soro lácteo das búfalas primíparas em comparação com as búfalas pluríparas, bem como a influência da fase da lactação nos parâmetros avaliados, como mencionado a seguir.

Contagem de células somáticas (CCS). Os valores da CCS encontrados nas amostras de leite dos três grupos que apresentaram reação negativa ao CMT e isolamento microbiológico negativo variaram de 1.000 a 199.000 células/ mL. Foi observado aumento da contagem de células somáticas ao longo da lactação nos três grupos experimentais. As búfalas com duas a três lactações (G2) apresentaram maior CCS no terço final da lactação (Quadro 1). Estes resultados são semelhantes aos encontrados por Bastos \& Birgel (2011), os quais observaram aumento significativo da contagem de células somáticas no leite de búfalas ao longo da lactação, com valores de CCS de 36.000 células/mL na fase inicial, 54.500 células/mL na fase intermediária e 95.500 células/mL na fase final da lactação. No início da lactação, observa-se um acréscimo no valor da CCS devido à maior quantidade de imunoglobulinas e, consequentemente, de células de defesa no colostro (Voltolini et al. 2001). No final da lactação, também se verifica um aumento na CCS, devido a uma maior descamação natural do epitélio da glândula mamária (Harmon \& Reneau 1993, Monardes 1994).

Perfil bioquímico. Gamaglutamiltransferase (GGT). As búfalas com duas ou três lactações (G2) apresentaram maior atividade de GGT na fase inicial da lactação em comparação com os demais grupos. Durante a lactação foi observado aumento significativo da atividade da GGT no soro lácteo das fêmeas primíparas (G1) da fase inicial para a fase intermediária e final da lactação. As búfalas pluríparas (G2 e G3) apresentaram aumento significativo da atividade de GGT da fase intermediária para a fase final da lactação 


\begin{tabular}{|c|c|c|c|}
\hline \multirow[t]{2}{*}{ Grupos } & \multicolumn{3}{|c|}{ Fases da lactação } \\
\hline & Inicial (I) & Intermediária (T) & Final (F) \\
\hline G1 & $23.600 \pm 25.200^{\mathrm{Aa}}(\mathrm{n}=109)$ & $31.200 \pm 22.900^{\mathrm{Ab}}(\mathrm{n}=116)$ & $34.400 \pm 35.200^{\mathrm{Aab}}(\mathrm{n}=79)$ \\
\hline G2 & $38.200 \pm 34.00^{\mathrm{Ba}}(\mathrm{n}=100)$ & $49.800 \pm 39.700^{\mathrm{Bab}}(\mathrm{n}=111)$ & $70.700 \pm 55.800^{\mathrm{Bb}}(\mathrm{n}=92)$ \\
\hline G3 & $55.500 \pm 48.100^{\mathrm{Bab}}(\mathrm{n}=78)$ & $46.400 \pm 40.300^{\mathrm{ABa}}(\mathrm{n}=130)$ & $61.500 \pm 52.200^{\mathrm{Bb}}(\mathrm{n}=108)$ \\
\hline
\end{tabular}

Médias seguidas de letras maiúsculas iguais na mesma coluna e letras minúsculas iguais na mesma linha não diferem entre si pelo teste de Tukey $(\mathrm{P}>0,05)$.

(Quadro 2). Estudos mostram que a GGT, além de estar envolvida com o transporte de aminoácidos do sangue para a glândula mamária, também participa da biossíntese das proteínas do leite (Baumrucker \& Pocius 1978), sugerindo que o aumento da atividade da referida enzima pode estar relacionado ao aumento da síntese dos constituintes do leite pelo do tecido mamário ao longo da lactação.

Fosfatase alcalina (ALP). Notou-se atividade significativamente maior da fosfatase alcalina no soro lácteo das fêmeas primíparas (G1) em relação às fêmeas pluríparas do G2 e do G3 nas diferentes fases da lactação. Também verificou-se aumento significativo da atividade desta enzima ao longo da lactação no soro lácteo dos animais de todos os grupos, com maiores valores no final da lactação (Quadro 2). Como a ALP está presente nas células mioepiteliais da glândula mamária (Fox \& Kelly 2006), acredita-se que sua atividade esteja associada ao mecanismo de produção de leite.

Proteína total (PT). Não se constatou diferença significativa entre as concentrações de proteína total do soro lácteo das búfalas primíparas (G1) e pluríparas (G2 e G3) ao longo da lactação. Verificou-se redução da concentração de proteína total no soro lácteo das fêmeas bubalinas dos três grupos experimentais entre a fase inicial e a fase intermediária da lactação, seguida de aumento na fase final da lactação (Quadro 2). De maneira semelhante, Hejtmánková et al. (2012) observaram maior concentração de proteína total no leite de cabras nas fases inicial e final da lactação e relacionaram este achado ao aumento da concentração de componentes do sistema imune (imunoglobulinas e proteínas de fase aguda). Lemos et al. (2013) também verificaram maiores concentrações de proteína total no soro lácteo de ovelhas aos 15 e 90 dias de lactação $(1,91 \pm 0,20 \mathrm{~g} / \mathrm{dL}$ e $1,91 \pm 0,17 \mathrm{~g} / \mathrm{dL}$, respectivamente) e menores concentrações aos 30 dias de lactação $(1,64 \pm 0,16 \mathrm{~g} / \mathrm{dL})$. Por outro lado, Raimondo et al. (2013) constataram maiores teores de proteína total no terço inicial $(810 \pm 150 \mathrm{mg} / \mathrm{dL})$ e no terço médio da lactação $(730 \pm 220 \mathrm{mg} / \mathrm{dL})$ de vacas da raça Jersey em comparação com o terço final da lactação $(380 \pm 160 \mathrm{mg} / \mathrm{dL})$.

Albumina. Não se verificou diferença significativa nas concentrações de albumina no soro lácteo das fêmeas primíparas (G1) e pluríparas (G2 e G3). Entretanto, ocorreu variação significativa da concentração da albumina entre a fase intermediária e final da lactação no soro lácteo das búfalas primíparas (G1) e com mais de três lactações (G3) (Quadro 2). Freitas Filho et al. (2009) constataram redução da síntese de caseína no leite de vacas ao longo da lactação e aumento de soroproteínas, dentre elas a albumina.
Cálcio total (Ca). Os teores de cálcio total foram maiores no soro lácteo das búfalas com mais de três lactações (G3). Estes valores diferiram significativamente daqueles obtidos no soro lácteo das fêmeas primíparas (G1) e com duas a três lactações (G2) na fase inicial, intermediária e final da lactação. Houve redução significativa da concentração de cálcio total no soro lácteo das fêmeas dos três grupos experimentais ao longo da lactação (Quadro 2). Estes resultados são semelhantes aos relatados por Gaucheron (2005), que também observou queda na concentração de cálcio total ao longo da lactação no leite de vacas.

Fósforo (P). Observou-se aumento da concentração de fósforo no soro lácteo das fêmeas primíparas (G1) e com duas a três lactações (G2) ao longo da lactação e das fêmeas com mais de três lactações (G3) entre a fase inicial e intemediária da lactação. Resultados semelhantes foram verificados por Rocha (2010) no soro lácteo de vacas primíparas e pluríparas.

Magnésio (Mg). As menores concentrações de magnésio foram observadas no soro lácteo das fêmeas primíparas (G1) na fase inicial da lactação e as maiores concentrações foram verificadas no soro lácteo das fêmeas com duas a três lactações (G2) na fase final da lactação. Houve aumento da concentração de magnésio no soro lácteo das búfalas primíparas (G1) e do G2 ao longo da lactação, e entre a fase inicial e intermediária da lactação nas fêmeas com mais de três lactações (G3) (Quadro 2). Segundo Gaucheron (2005), a concentração de magnésio no leite bovino varia muito pouco ao longo da lactação.

Cloretos (Cl). As fêmeas primíparas (G1) apresentaram menores concentrações de cloretos no soro lácteo na fase inicial da lactação, enquanto que as fêmeas com duas a três lactações (G2) apresentaram a maior concentração de cloretos na fase final da lactação. Durante a lactação não foram constatadas variações significativas das concentrações de cloretos no soro lácteo dos animais avaliados (Quadro 2). Por outro lado, Bastos \& Birgel (2011) observaram aumento significativo da concentração de cloretos no leite de fêmeas bubalinas mais velhas e na fase final da lactação e relacionaram este achado ao maior número de isolamentos bacterianos no decorrer das lactações. Zafalon et al. (2005) relataram aumento progressivo da concentração de cloretos no leite de vacas e atribuíram este aumento à possíveis descamações das células secretoras da glândula mamária.

Ferro (Fe). Constatou-se diminuição da concentração de ferro no soro lácteo dos animais de todos os grupos ao longo da lactação, sendo esta significativa nas búfalas pri- 


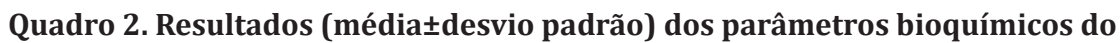
soro lácteo de búfalas Murrah primíparas (G1), com duas a três lactações (G2) e com mais de três lactações (G3) ao longo das fases da lactação

\begin{tabular}{|c|c|c|c|}
\hline \multirow[t]{2}{*}{ Parâmetros/Grupos } & \multicolumn{3}{|c|}{ Fases da lactação } \\
\hline & Inicial (I) & Intermediária (T) & Final $(F)$ \\
\hline \multicolumn{4}{|l|}{$\begin{array}{l}\text { Gamaglutamiltransferase } \\
\text { (GGT; U/L) }\end{array}$} \\
\hline G1 & $1.662 \pm 532^{\mathrm{Aa}}(\mathrm{n}=109)$ & $1.866 \pm 449^{\mathrm{Ab}}(\mathrm{n}=116)$ & $2.346 \pm 413^{\mathrm{Ac}}(\mathrm{n}=79)$ \\
\hline G2 & $1.837 \pm 616^{\mathrm{Ba}}(\mathrm{n}=100)$ & $1.873 \pm 516^{\mathrm{Aa}}(\mathrm{n}=111)$ & $2.125 \pm 423^{\mathrm{Ab}}(\mathrm{n}=92)$ \\
\hline G3 & $1.669 \pm 581^{\mathrm{ABa}}(\mathrm{n}=78)$ & $1.832 \pm 383^{\mathrm{Aa}}(\mathrm{n}=130)$ & $2.174 \pm 534^{\mathrm{Ab}}(\mathrm{n}=108)$ \\
\hline \multicolumn{4}{|l|}{$\begin{array}{l}\text { Fosfatase alcalina } \\
\text { (ALP; U/L) }\end{array}$} \\
\hline $\mathrm{G} 1$ & $43,1 \pm 24,2^{\mathrm{Aa}}(\mathrm{n}=109)$ & $95,1 \pm 41,2^{\mathrm{Ab}}(\mathrm{n}=116)$ & $181 \pm 81,0^{A c}(n=79)$ \\
\hline G2 & $33,9 \pm 16,4 A^{\text {Ba }}(n=100)$ & $80,1 \pm 46,9^{\mathrm{Bb}}(\mathrm{n}=111)$ & $166 \pm 110^{\mathrm{ABC}}(\mathrm{n}=92)$ \\
\hline G3 & $29,5 \pm 24,1^{\mathrm{Ba}}(\mathrm{n}=78)$ & $75,4 \pm 46,3^{\mathrm{Bb}}(\mathrm{n}=130)$ & $138 \pm 95,7^{\mathrm{Bc}}(\mathrm{n}=108)$ \\
\hline \multicolumn{4}{|l|}{ Proteína total (g/dL) } \\
\hline G1 & $1,45 \pm 0,21^{\mathrm{Aa}}(\mathrm{n}=109)$ & $1,38 \pm 0,16^{\mathrm{Ab}}(\mathrm{n}=116)$ & $1,54 \pm 0,12^{\mathrm{Aa}}(\mathrm{n}=79)$ \\
\hline G2 & $1,49 \pm 0,21^{\mathrm{Aab}}(\mathrm{n}=100)$ & $1,44 \pm 0,13^{\mathrm{Aa}}(\mathrm{n}=111)$ & $1,55 \pm 0,17^{\mathrm{Ab}}(\mathrm{n}=92)$ \\
\hline G3 & $1,46 \pm 0,23^{\mathrm{Aab}}(\mathrm{n}=78)$ & $1,40 \pm 0,11^{\mathrm{Aa}}(\mathrm{n}=130)$ & $1,52 \pm 0,15^{\mathrm{Ab}}(\mathrm{n}=108)$ \\
\hline \multicolumn{4}{|l|}{ Albumina (mg/dL) } \\
\hline $\mathrm{G} 1$ & $80,0 \pm 40,0^{\text {Aa }}(\mathrm{n}=109)$ & $80,0 \pm 40,0^{\text {Aa }}(\mathrm{n}=116)$ & $90,0 \pm 20,0^{\mathrm{Ab}}(\mathrm{n}=79)$ \\
\hline G2 & $80,0 \pm 40,0^{\mathrm{Aa}}(\mathrm{n}=100)$ & $100 \pm 110^{\mathrm{Aa}}(\mathrm{n}=111)$ & $90,0 \pm 20,0^{\mathrm{Aa}}(\mathrm{n}=92)$ \\
\hline G3 & $90,0 \pm 140^{\text {Aa }}(\mathrm{n}=78)$ & $80,0 \pm 90,0^{\text {Aa }}(n=130)$ & $90,0 \pm 20,0^{\mathrm{Ab}}(\mathrm{n}=108)$ \\
\hline \multicolumn{4}{|l|}{ Cálcio total (mg/dL) } \\
\hline $\mathrm{G} 1$ & $38,9 \pm 6,84^{\text {Aa }}(n=109)$ & $32,3 \pm 4,80^{\mathrm{Ab}}(\mathrm{n}=116)$ & $29,5 \pm 4,12^{\mathrm{Ac}}(\mathrm{n}=79)$ \\
\hline G2 & $38,2 \pm 7,13^{\mathrm{Aa}}(\mathrm{n}=100)$ & $31,5 \pm 3,86^{\mathrm{Ab}}(\mathrm{n}=111)$ & $28,8 \pm 4,70^{\mathrm{Ab}}(\mathrm{n}=92)$ \\
\hline G3 & $41,8 \pm 8,14^{\mathrm{Ba}}(\mathrm{n}=78)$ & $35,2 \pm 5,45^{\mathrm{Bb}}(\mathrm{n}=130)$ & $32,4 \pm 6,77^{\mathrm{Bc}}(\mathrm{n}=108)$ \\
\hline \multicolumn{4}{|l|}{ Fósforo $(\mathrm{mg} / \mathrm{dL})$} \\
\hline G1 & $39,3 \pm 6,04 \mathrm{~A}^{\mathrm{Ba}}(\mathrm{n}=109)$ & $50,4 \pm 7,21^{\mathrm{Ab}}(\mathrm{n}=116)$ & $56,6 \pm 10,1^{\text {Ac }}(n=79)$ \\
\hline G2 & $42,8 \pm 8,48^{\mathrm{Ba}}(\mathrm{n}=100)$ & $51,2 \pm 8,96^{\mathrm{Ab}}(\mathrm{n}=111)$ & $51,4 \pm 10,2^{\mathrm{Bb}}(\mathrm{n}=92)$ \\
\hline G3 & $38,3 \pm 11,1^{\text {Aa }}(n=78)$ & $44,2 \pm 11,3^{\mathrm{Bb}}(\mathrm{n}=130)$ & $40,8 \pm 11,6^{\mathrm{Cc}}(\mathrm{n}=108)$ \\
\hline \multicolumn{4}{|l|}{ Magnésio (mg/dL) } \\
\hline $\mathrm{G} 1$ & $7,34 \pm 1,20^{\text {Aa }}(\mathrm{n}=109)$ & $7,50 \pm 1,09^{\mathrm{Aa}}(\mathrm{n}=116)$ & $8,19 \pm 1,37^{\mathrm{Aa}}(\mathrm{n}=79)$ \\
\hline G2 & $7,59 \pm 1,44^{\mathrm{Aa}}(\mathrm{n}=100)$ & $7,91 \pm 1,27^{\mathrm{ABa}}(\mathrm{n}=111)$ & $8,80 \pm 1,28^{\mathrm{Ab}}(\mathrm{n}=92)$ \\
\hline G3 & $7,65 \pm 1,59^{\text {Aa }}(n=78)$ & $8,04 \pm 1,26^{\mathrm{Ba}}(\mathrm{n}=130)$ & $7,95 \pm 3,30^{\mathrm{Aa}}(\mathrm{n}=108)$ \\
\hline \multicolumn{4}{|l|}{ Cloretos (mEq/L) } \\
\hline $\mathrm{G} 1$ & $159 \pm 24,1^{\mathrm{Ba}}(\mathrm{n}=109)$ & $170 \pm 17,5^{\mathrm{Aa}}(\mathrm{n}=116)$ & $168 \pm 22,2^{\mathrm{ABa}}(\mathrm{n}=79)$ \\
\hline G2 & $171 \pm 25,7^{\mathrm{Aa}}(\mathrm{n}=100)$ & $173 \pm 21,1^{\mathrm{Aa}}(\mathrm{n}=111)$ & $176 \pm 25,7^{\mathrm{Ba}}(\mathrm{n}=92)$ \\
\hline G3 & $165 \pm 21,3^{\mathrm{Aa}}(\mathrm{n}=78)$ & $166 \pm 15,6^{\text {Aa }}(n=130)$ & $163 \pm 26,3^{\mathrm{Aa}}(\mathrm{n}=108)$ \\
\hline \multicolumn{4}{|l|}{ Ferro $(\mu \mathrm{g} / \mathrm{dL})$} \\
\hline G1 & $6,96 \pm 18,4^{\text {Aa }}(\mathrm{n}=109)$ & $6,67 \pm 10,5^{\mathrm{Ab}}(\mathrm{n}=116)$ & $5,35 \pm 6,25^{\mathrm{Ab}}(\mathrm{n}=79)$ \\
\hline G2 & $10,7 \pm 24,0^{\mathrm{Aa}}(\mathrm{n}=100)$ & $7,61 \pm 17,3^{\text {Aa }}(\mathrm{n}=111)$ & $6,29 \pm 8,82^{\mathrm{Aa}}(\mathrm{n}=92)$ \\
\hline G3 & $9,44 \pm 22,1^{\text {Aa }}(n=78)$ & $6,24 \pm 17,3^{\mathrm{Aa}}(\mathrm{n}=130)$ & $5,35 \pm 7,77^{\mathrm{Aa}}(\mathrm{n}=108)$ \\
\hline \multicolumn{4}{|l|}{$\begin{array}{l}\text { Cálcio Ionizado } \\
\text { (mMol/L) }\end{array}$} \\
\hline G1 & $2,57 \pm 0,41^{\mathrm{Aa}}(\mathrm{n}=109)$ & $2,58 \pm 0,34^{\mathrm{Aa}}(\mathrm{n}=116)$ & $2,30 \pm 0,38^{\mathrm{Ab}}(\mathrm{n}=79)$ \\
\hline G2 & $2,62 \pm 0,48^{\mathrm{Aa}}(\mathrm{n}=100)$ & $2,55 \pm 0,34^{\mathrm{Aa}}(\mathrm{n}=111)$ & $2,38 \pm 0,39^{\mathrm{Ab}}(\mathrm{n}=92)$ \\
\hline G3 & $2,76 \pm 0,37^{\mathrm{Ba}}(\mathrm{n}=78)$ & $2,92 \pm 0,50^{\mathrm{Ba}}(\mathrm{n}=130)$ & $2,72 \pm 0,54^{\mathrm{Bb}}(\mathrm{n}=108)$ \\
\hline \multicolumn{4}{|l|}{ Sódio (mMol/L) } \\
\hline G1 & $156 \pm 24,2^{\mathrm{Aa}}(\mathrm{n}=109)$ & $167 \pm 16,4^{\mathrm{Ab}}(\mathrm{n}=116)$ & $174 \pm 16,2^{\mathrm{Ab}}(\mathrm{n}=79)$ \\
\hline G2 & $162 \pm 23,5^{\mathrm{Aa}}(\mathrm{n}=100)$ & $172 \pm 18,2^{\mathrm{Ab}}(\mathrm{n}=111)$ & $178 \pm 11,8^{\mathrm{Ab}}(\mathrm{n}=92)$ \\
\hline G3 & $161 \pm 21,0^{\text {Aa }}(n=78)$ & $166 \pm 15,9^{\mathrm{Ab}}(\mathrm{n}=130)$ & $169 \pm 15,3^{\mathrm{Ab}}(\mathrm{n}=108)$ \\
\hline \multicolumn{4}{|l|}{ Potássio (mMol/L) } \\
\hline G1 & $32,0 \pm 5,56^{\mathrm{Aa}}(\mathrm{n}=109)$ & $28,4 \pm 4,95^{\mathrm{Ab}}(\mathrm{n}=116)$ & $28,0 \pm 2,64^{\mathrm{Ab}}(\mathrm{n}=79)$ \\
\hline G2 & $31,6 \pm 5,20^{\mathrm{Aa}}(\mathrm{n}=100)$ & $28,6 \pm 2,78^{\mathrm{Ab}}(\mathrm{n}=111)$ & $27,2 \pm 2,81^{\mathrm{Ab}}(\mathrm{n}=92)$ \\
\hline G3 & $31,9 \pm 5,41^{\text {Aa }}(n=78)$ & $27,1 \pm 2,66^{\mathrm{Ab}}(\mathrm{n}=130)$ & $27,3 \pm 2,27^{\mathrm{Ab}}(\mathrm{n}=108)$ \\
\hline
\end{tabular}

Médias seguidas de letras maiúsculas iguais na mesma coluna e letras minúsculas iguais na mesma linha não diferem entre si pelo teste de Tukey $(\mathrm{P}>0,05)$.

míparas (G1) (Quadro 2). Resultados semelhantes foram observados por Górska \& Oprzadek (2011), que constataram menores concentrações de ferro no leite de novilhas e maiores concentrações no leite de vacas pluríparas, porém sem diferença significativa. Segundo Dorea (2000), algumas das propriedades bacteriostáticas do leite estão estreitamente associadas à concentração e à biodisponibilidade do ferro.
Cálcio ionizado (Cai). As maiores concentrações de cálcio ionizado foram verificadas no soro lácteo das búfalas com mais de três lactações (G3). Constatou-se diminuição significativa da concentração de cálcio ionizado no soro lácteo das búfalas dos três grupos experimentais entre a fase inicial e a fase final da lactação (Quadro 2). De acordo com Górska \& Oprzadek (2011) a concentração dos minerais no leite pode variar significativamente, já que depende de vá- 
rios fatores, dentre eles a nutrição e o estado fisiológico do animal.

Sódio (Na). Notou-se aumento da concentração de sódio no soro lácteo de fêmeas primíparas (G1) e pluríparas (G2 e G3) ao longo da lactação (Quadro 2). Segundo Zafalon et al. (2005), o aumento da concentração de sódio ao longo da lactação pode estar relacionado ao aumento da descamação do tecido mamário, que altera a permeabilidade das junções paracelulares do tecido mamário acarretando maior extravasamento deste íon para o leite.

Potássio (K). Constatou-se redução significativa das concentrações de potássio no soro lácteo das búfalas de todos os grupos entre a fase inicial e final da lactação (Quadro 2). De acordo com Arney \& Philips (2005), a redução dos teores de potássio pode estar relacionada à manutenção do equilíbrio osmótico, uma vez que o aumento da concentração de sódio ocasiona diminuição da concentração de potássio no leite.

Fracionamento eletroforético (SDS-PAGE): 0 fracionamento eletroforético das proteínas do soro lácteo das búfalas primíparas (G1) e pluríparas (G2 e G3) possibilitou a detecção de até 24 proteínas, cujos pesos moleculares variaram de 12.000 a 235.000 dáltons (Da). Destas, foram analisadas imunoglobulina A - IgA (160.000 Da), lactoferrina (79.500 $\mathrm{Da})$, albumina sérica (64.000 Da), imunoglobulina G - IgG (83.000 Da), $\beta$-lactoglobulina (18.500 Da) e $\alpha$-lactoalbumina
(15.000 Da) em razão da sua importância para avaliação do estado de saúde da glândula mamária (Fig.1).

Imunoglobulina A (IgA). Não se constatou diferença significativa na concentração de IgA entre os grupos ao longo da lactação (Quadro 3). Constatou-se queda desta imu-

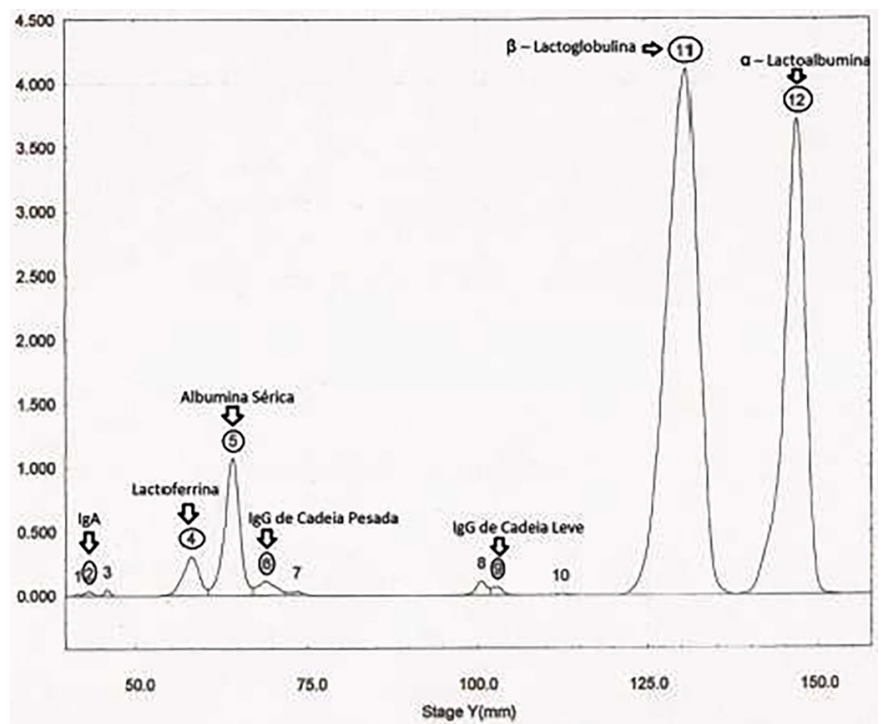

Fig.1. Traçado densitométrico do proteinograma do soro lácteo de búfala Murrah sadia.

Quadro 3. Resultados (média \pm desvio padrão) das proteínas obtidas pelo fracionamento eletroforético em gel de poliacrilamida contendo dodecil sulfato de sódio (SDS-PAGE) do soro lácteo de búfalas primíparas (G1), com duas a três lactações (G2) e com mais de três lactações (G3) ao longo das fases da lactação

\begin{tabular}{cccc}
\hline Proteínas/Grupos & \multicolumn{3}{c}{ Fases da lactação } \\
\cline { 2 - 4 } & Inicial $(\mathrm{I})$ & Intermediária $(T)$ & Final $(\mathrm{F})$ \\
\hline IgA (mg/dL) & & & \\
G1 & $0,57 \pm 1,59^{\mathrm{Aa}}(\mathrm{n}=109)$ & $0,16 \pm 0,56^{\mathrm{Aa}}(\mathrm{n}=116)$ & $0,19 \pm 0,59^{\mathrm{Aa}}(\mathrm{n}=79)$ \\
G2 & $0,52 \pm 1,00^{\mathrm{Aa}}(\mathrm{n}=100)$ & $0,09 \pm 0,29^{\mathrm{Aa}}(\mathrm{n}=111)$ & $0,51 \pm 1,44^{\mathrm{Aa}}(\mathrm{n}=92)$ \\
G3 & $0,59 \pm 1,24^{\mathrm{Aa}}(\mathrm{n}=78)$ & $0,23 \pm 0,57^{\mathrm{Aa}}(\mathrm{n}=130)$ & $1,32 \pm 3,47^{\mathrm{Aa}}(\mathrm{n}=108)$ \\
Lactoferrina & & & \\
(mg/dL) & & & \\
G1 & $26,7 \pm 10,1^{\mathrm{Aa}}(\mathrm{n}=109)$ & $26,6 \pm 7,85^{\mathrm{Aa}}(\mathrm{n}=116)$ & $38,0 \pm 13,8^{\mathrm{Aa}}(\mathrm{n}=79)$ \\
G2 & $26,4 \pm 9,43^{\mathrm{Aa}}(\mathrm{n}=100)$ & $26,4 \pm 11,3^{\mathrm{Aa}}(\mathrm{n}=111)$ & $59,5 \pm 45,5^{\mathrm{ABb}}(\mathrm{n}=92)$ \\
G3 & $31,7 \pm 21,4^{\mathrm{Aa}}(\mathrm{n}=78)$ & $24,9 \pm 7,80^{\mathrm{Aa}}(\mathrm{n}=130)$ & $55,4 \pm 28,3^{\mathrm{Bb}}(\mathrm{n}=108)$ \\
Albumina sérica & & & \\
(mg/dL) & & & \\
G1 & $65,4 \pm 21,1^{\mathrm{Aa}}(\mathrm{n}=109)$ & $68,1 \pm 21,8^{\mathrm{Aa}}(\mathrm{n}=116)$ & $73,5 \pm 22,8^{\mathrm{Aa}}(\mathrm{n}=79)$ \\
G2 & $67,6 \pm 23,6^{\mathrm{Aa}}(\mathrm{n}=100)$ & $73,1 \pm 26,4^{\mathrm{Aa}}(\mathrm{n}=111)$ & $95,8 \pm 55,3^{\mathrm{ABa}}(\mathrm{n}=92)$ \\
G3 & $66,7 \pm 26,0^{\mathrm{Aa}}(\mathrm{n}=78)$ & $65,1 \pm 25,9^{\mathrm{Aa}}(\mathrm{n}=130)$ & $99,1 \pm 36,2^{\mathrm{Bb}}(\mathrm{n}=108)$ \\
IgG (mg/dL) & & & \\
G1 & $24,4 \pm 69,8^{\mathrm{Aa}}(\mathrm{n}=109)$ & $15,4 \pm 8,55^{\mathrm{Ab}}(\mathrm{n}=116)$ & $19,9 \pm 10,2^{\mathrm{Ab}}(\mathrm{n}=79)$ \\
G2 & $17,0 \pm 12,2^{\mathrm{Aa}}(\mathrm{n}=100)$ & $15,4 \pm 8,57^{\mathrm{Aa}}(\mathrm{n}=111)$ & $37,1 \pm 39,2^{\mathrm{Ab}}(\mathrm{n}=92)$ \\
G3 & $25,4 \pm 33,7^{\mathrm{Aa}}(\mathrm{n}=78)$ & $20,6 \pm 14,0^{\mathrm{Aa}}(\mathrm{n}=130)$ & $49,7 \pm 54,7^{\mathrm{Aa}}(\mathrm{n}=108)$ \\
B-lactoglobulina & & & \\
(mg/dL) & & & \\
G1 & $971 \pm 224^{\mathrm{Aab}}(\mathrm{n}=109)$ & $850 \pm 147^{\mathrm{Aa}}(\mathrm{n}=116)$ & $925 \pm 111^{\mathrm{Aa}}(\mathrm{n}=79)$ \\
G2 & $998 \pm 280^{\mathrm{Aa}}(\mathrm{n}=100)$ & $915 \pm 186^{\mathrm{Aa}}(\mathrm{n}=111)$ & $889 \pm 216^{\mathrm{Aa}}(\mathrm{n}=92)$ \\
G3 & $1.068 \pm 340^{\mathrm{Aab}}(\mathrm{n}=78)$ & $838 \pm 207^{\mathrm{Aa}}(\mathrm{n}=130)$ & $895 \pm 176^{\mathrm{Aa}}(\mathrm{n}=108)$ \\
$\alpha$-lactoalbumina & & & \\
(mg/dL) & & & \\
G1 & $312 \pm 198^{\mathrm{Aa}}(\mathrm{n}=109)$ & $387 \pm 169^{\mathrm{Ab}}(\mathrm{n}=116)$ & $458 \pm 74^{\mathrm{Ab}}(\mathrm{n}=79)$ \\
G2 & $337 \pm 185^{\mathrm{Aa}}(\mathrm{n}=100)$ & $373 \pm 167^{\mathrm{Aa}}(\mathrm{n}=111)$ & $357 \pm 162^{\mathrm{Aa}}(\mathrm{n}=92)$ \\
G3 & $326 \pm 202^{\mathrm{Aa}}(\mathrm{n}=78)$ & $427 \pm 132^{\mathrm{Aa}}(\mathrm{n}=130)$ & $436 \pm 140^{\mathrm{Aa}}(\mathrm{n}=108)$
\end{tabular}

Médias seguidas de letras maiúsculas iguais na mesma coluna e letras minúsculas iguais na mesma linha não diferem entre si pelo teste de Tukey $(P>0,05)$. 
noglobulina entre a fase inicial e a fase intermediária da lactação, seguida de aumento na fase final da lactação em todos os grupos avaliados. Esses resultados são semelhantes aos obtidos por Lemos et al. (2013), que também verificaram diminuição da concentração de IgA no soro lácteo de ovelhas ao longo da lactação. Segundo Kocina et al. (2012), a IgA é importante na proteção do tecido mamário e sua concentração varia consideravelmente entre os indivíduos.

Lactoferrina. Constatou-se diminuição da concentração de lactoferrina no soro lácteo das búfalas primíparas (G1) e pluríparas (G2 e G3) entre a fase inicial e a fase intermediária da lactação, com aumento na fase final da lactação. As búfalas com duas a três lactações (G2) apresentaram os maiores valores de lactoferrina na fase final da lactação (Quadro 3). Newman et al. (2009) também relataram aumento da concentração de lactoferrina no período que antecede a secagem das vacas. Por outro lado, Raimondo et al. (2013) verificaram redução da concentração de lactoferrina no soro lácteo de vacas durante a lactação, com maiores valores no terço inicial $(60,0 \pm 20,0 \mathrm{mg} / \mathrm{dL})$ e no terço médio da lactação $(50,0 \pm 20,0 \mathrm{mg} / \mathrm{dL})$ e menores no terço final da lactação $(30,0 \pm 20,0 \mathrm{mg} / \mathrm{dL})$. A lactoferrina exerce um importante papel na proteção da glândula mamária, uma vez que esta proteína sequestra o ferro tornando-o indisponível para os micro-organismos e dificultando o crescimento destes (Newman et al. 2009).

Albumina sérica. Constatou-se aumento da concentração de albumina sérica no soro lácteo das fêmeas primíparas (G1) e pluríparas (G2 e G3) da fase inicial para a fase final da lactação. As fêmeas com mais de três lactações (G3) apresentaram a maior concentração de albumina sérica no soro lácteo na fase final da lactação (Quadro 3). Por outro lado, Sant'Ana (2004) notou maior teor de albumina sérica no soro lácteo de vacas primíparas $(75,7 \mathrm{mg} / \mathrm{dL})$. Raimondo et al. (2013) constataram influência da fase da lactação na concentração de albumina sérica no soro lácteo de vacas, com maiores valores no terço inicial $(30,0 \pm 10,0 \mathrm{mg} / \mathrm{dL})$ e no terço médio da lactação $(40,0 \pm 20,0 \mathrm{mg} / \mathrm{dL})$ em relação ao terço final da lactação $(10,0 \pm 10,0 \mathrm{mg} / \mathrm{dL})$. A avaliação do teor desta proteína no soro lácteo pode ser um importante indicador de inflamação mamária, pois sua concentração se eleva durante a inflamação devido ao aumento da permeabilidade vascular (Sant'Ana et al. 2006).

Imunoglobulina G (IgG). Notou-se diminuição da concentração de IgG no soro lácteo das fêmeas primíparas (G1) e pluríparas (G2 e G3) entre a fase inicial e a fase intermediária da lactação, seguida por aumento na fase final da lactação (Quadro 3). Sant'Ana (2004) verificou teores de IgG de $134 \mathrm{mg} / \mathrm{dL}, 117 \mathrm{mg} / \mathrm{dL}$ e $143 \mathrm{mg} / \mathrm{dL}$ no soro lácteo de bovinos de primeira lactação, de segunda ou terceira lactações e de quarta ou mais lactações, respectivamente, porém, não relatou variação significativa da concentração de $\operatorname{IgG}$ ao longo das fases da lactação. Por outro lado, Raimondo et al. (2013) relataram influência da fase da lactação nos teores de imunoglobulinas no soro lácteo de vacas, verificando maiores valores no terço inicial e no terço médio da lactação, em relação aos observados no terço final da lactação. A IgG tem grande importância no processo de transferência de imunidade passiva, sendo verificado valores elevados desta imunoglobulina na fase colostral (Rocha 2010), os quais diminuem rapidamente, atingindo valores mínimos no leite (Georgiev 2008).

$\beta$-lactoglobulina. Constatou-se redução da concentração de $\beta$-lactoglobulina no soro lácteo das búfalas de todos os grupos entre a fase inicial e a fase intermediária da lactação, seguida de aumento no soro lácteo das búfalas primíparas (G1) e com mais de três lactações (G3) na fase final da lactação e diminuição da concentração desta proteína no soro lácteo das búfalas com duas a três lactações (G2) (Quadro 3). Raimondo et al. (2013) também constataram diminuição da concentração desta proteína no soro lácteo de fêmeas bovinas ao longo da lactação (terço inicial: $280 \pm 60,0 \mathrm{mg} / \mathrm{dL}$, terço médio: $260 \pm 60,0 \mathrm{mg} / \mathrm{dL}$ e terço final da lactação: $150 \pm 70,0 \mathrm{mg} / \mathrm{dL}$ ). Segundo Sawyer (2003), a $\beta$-lactoglobulina pode desempenhar um papel importante no metabolismo de fosfato na glândula mamária, no transporte de vitamina A e de outras moléculas no trato gastrointestinal de neonatos.

$\boldsymbol{\alpha}$-lactoalbumina. Constatou-se aumento da concentração de $\alpha$-lactoalbumina no soro lácteo das fêmeas bubalinas primíparas (G1) e pluríparas (G2 e G3) da fase inicial para a fase intermediária da lactação, seguido de aumento no soro lácteo das búfalas primíparas (G1) e com mais de três lactações (G3) na fase final da lactação e diminuição da concentração desta proteína no soro lácteo das búfalas com duas a três lactações (G2) (Quadro 3). Por outro lado, Raimondo et al. (2013) observaram redução na concentração de $\alpha$-lactoalbumina no soro lácteo de vacas Jersey ao longo da lactação (terço inicial: $190 \pm 40,0 \mathrm{mg} / \mathrm{dL}$, terço médio: $150 \pm 40,0 \mathrm{mg} / \mathrm{dL}$ e terço final da lactação: $70,0 \pm 50,0 \mathrm{mg} /$ dL). Segundo Farrell et al. (2004), a redução do teor de $\alpha$-lactoalbumina está correlacionada com a queda da concentração de lactose que ocorre no final da lactação.

\section{CONCLUSÕES}

Notou-se influência da ordem de parto e da fase da lactação no perfil bioquímico e no proteinograma do soro lácteo de búfalas da raça Murrah sadias.

Os resultados obtidos podem ser utilizados como referências para a espécie bubalina e auxiliar no diagnóstico e no prognóstico de doenças de ocorrência comum na fase de lactação.

Além disso, de especial interesse é a determinação das concentrações de proteínas de fase aguda, como possíveis biomarcadores precoces de enfermidades infecciosas e/ou inflamatórias, cuja literatura a respeito é escassa nesta espécie animal.

Agradecimentos.- À Fundação de Amparo à Pesquisa do Estado de São Paulo (FAPESP) pela bolsa de estudo (Processo 2011/03514-0) e auxílio financeiro (Processo 2011/19480-7).

\section{REFERÊNCIAS}

Andrade K.D., Rangel A.H.N., Araújo V.M., Lima Júnior D.M. \& Oliveira N.A. 2011. Efeito da estação do ano na qualidade do leite de búfalas. Revta Verde Agroecologia Desenvolv. Sustent. 6(3):33-37.

Arney D.R. \& Philips C.J. 2005. The effects of changes in sodium and potassium concentration on the growth of mastitogenic bacteria in vitro. Int. J. Appl. Res. Vet. Med. 3(3):242-248. 
Bastos P.A.S. \& Birgel E.H. 2011. Leite de búfalas Murrah criadas em São Paulo (Brasil): influência da idade, fase de lactação, momento da ordenha e isolamento bacteriano na composição físico-química e celular. Revta Educ. Contin. Med. Vet. Zootec. CRMV-SP 9(3):6-13.

Baumrucker C.R. \& Pocius P.A. 1978. Gamma-glutamyl transpeptidase in lactating mammary secretory tissue of cow and rat. J. Dairy Sci. 61(3):309-314.

Baroza P.F.J. 2007. Proteínas, enzimas e minerais na secreção láctea de cabras e vacas, nos primeiros 30 dias pós-parto, congelada ou não. Dissertação de Mestrado em Clínica Médica Veterinária, Faculdade de Ciências Agrárias e Veterinárias, Universidade Estadual Paulista "Júlio de Mesquita Filho", Jaboticabal, SP. 87p.

Ceciliani F., Ceron J.J., Eckersall P.D. \& Sauerwein H. 2012. Acute phase proteins in ruminants. J. Proteomics 75(14):4207-4231.

Dorea J.G. 2000. Iron and copper in human milk. Nutrition 16(3):209-220.

Farrell H.M., Flores-Jimenez R., Bleck G.T., Brown E.M., Butler J.E., Creamer L.K., Hicks C.L., Holler C.M., Ng-Kwai-Hang K.F. \& Swaisgood H.E. 2004. Nomenclature of the proteins of cows' milk: sixth revision. J. Dairy Sci. 87(6):1641-1674.

Fox P.F. \& Kelly A.L. 2006. Indigenous enzymes in milk: overview and historical aspects - Part 2. Int. Dairy J. 16(6):517-532.

Freitas Filho J.R., Freitas W.R., Lima R.S., Silva M.S.J., Lima R.T., Souza H.B. \& Lima V.A.M. 2009. Avaliação do teor de caseína e albumina no leite de vacas da raça Girolanda. Revta Bras. Tec. Agro. 3(1):42-48.

Ganheim C., Alenius S. \& Waller K.P. 2007. Acute phase proteins as indicators of calf herd health. Vet. J. 173(3):645-646.

Gaucheron F. 2005. The minerals of milk. Reprod. Nutr. Dev. 45(4):473483.

Georgiev I.P. 2008. Differences in chemical composition between cow colostrum and milk. Bulg. J. Vet. Med. 11(1):3-12.

Górska A. \& Oprzadek K. 2011. Concentration of trace elements in raw milk depending on the lactation period and age of cows. Acta Vet., Brno, 80(2):203-206.

Harmon R.J. \& Reneau J.K. 1993. Factors affecting somatic cell counts in milk. Proc. $32^{\text {nd }}$ National Mastitis Council Annual Meeting, Kansas City, MO, USA, p.35-38.

Hejtmánková A., Pivec V., Trnková E. \& Dragounová H. 2012. Differences in the composition of total and whey proteins in goat and ewe milk and their changes throughout the lactation period. Czech J. Anim. Sci. 57(7):323-331.

IBGE 2014. Produção da Pecuária Municipal 2013. Instituto Brasileiro de Geografia e Estatística. Disponível em <http://www.ibge.gov.br/home/ estatistica/economia/ppm/2013/default.shtm> Acesso em 25 dez. 2014.

Kocina I., Antane V. \& Lusis I. 2012. The concentration of immunoglobulins $\mathrm{A}, \mathrm{G}$, and $\mathrm{M}$ in cow milk and blood in relation with cow seasonal keeping and pathogens presence in the udder. Proc. Latv. Univ. Agr. 27(322): 44-53.

Laemmli U.K. 1970. Cleavage of structural proteins during the assembly of the head of bacteriophage T4. Nature 227(5259):680-685.

Langoni H., Domingues P.F., Molero Filho J.R. \& Baldini S. 2001. Etiologia e sensibilidade bacteriana da mastite subclínica em búfalos (Bubalus bubalis). Ars Vet. 17(3):213-217.

Lemos V.F., Guaraná E.L.S., Afonso J.A.B., Fagliari J.J., Silva P.C., Soares P.C. \& Mendonça C.L. 2013. Proteinograma do soro lácteo de ovelhas da raça Santa Inês em diferentes fases da lactação. Pesq. Vet. Bras. 33(6): 807-812.

Martins Filho L.P. 2006. Inoculação intramamária de Staphylococcus aureus (Estirpe ATCC 25923) em vacas leiteiras: estudo clínico, labora- torial e terapêutico. Tese de Doutorado em Clínica Médica Veterinária, Faculdade de Ciências Agrárias e Veterinárias, Universidade Estadual Paulista "Júlio de Mesquita Filho", Jaboticabal, SP. 74p.

Monardes H. 1994. Somatic cell counting and genetic improvement of resistance to mastitis. Anais 31a Reunião da Sociedade Brasileira de Zootecnia, Maringá, PR, p.1-19.

Newman K.A., Rajala-Schultz P.J., Lakritz J. \& Degraves F.J. 2009. Lactoferrin concentrations in bovine milk prior to dry-off. J. Dairy Res. 76(4):426-432

Patel D.A., Silva C.V. \& Sannabhadti S.S. 1993. Sources of microbial contamination of raw milk. Indian J. Dairy Sci. 46(2):67-70.

Quinn P.J., Markey B., Carter M.E., Donnelly W.J. \& Leonard F.C. 2005. Microbiologia veterinária e doenças infecciosas. Artmed, Porto Alegre. 512p.

Radostits O.M., Gay C.C., Blood D.C. \& Hinchcliff K.W. 2007. Diseases of the mammary gland, p.673-763. In: Veterinary Medicine: a textbook of the diseases of cattle, horses, sheep, pigs, and goats. $10^{\text {th }}$ ed. W.B. Saunders, Philadelphia.

Raimondo R.F.S., Miyiashiro S.I., Mori S.C. \& Birgel Junior E.H. 2013. Proteínas do soro lácteo de vacas da raça Jersey durante a lactação. Pesq. Vet. Bras. 33(1):119-125.

Rocha T.G. 2010. Avaliação da transferência de imunidade passiva em bezerros de vacas da raça Canchim. Dissertação de Mestrado em Clínica Médica Veterinária, Faculdade de Ciências Agrárias e Veterinárias, Universidade Estadual Paulista "Júlio de Mesquita Filho", Jaboticabal, SP. 108 .

Rocha T.G., Franciosi C., Nociti R.P., Silva P.C., Sampaio A.A.M. \& Fagliari J.J. 2014. Influence of parity on concentration of enzymes, proteins, and minerals in the milk of cows. Arq. Bras. Med. Vet. Zootec. 66(1):315-320.

Sant’Ana V.A.C. \& Birgel E.H. 2003. Obtenção do soro lácteo para o fracionamento das proteínas por eletroforese em gel de poliacrilamida. Anais 9o Congresso Latinoamericano de Buiatria, 5ํㅡ Congresso Brasileiro de Buiatria, $3^{\circ}$ Congresso Nordestino de Buiatria, Salvador, BA, p.31. (Resumo)

Sant'Ana V.A.C. 2004. Proteinograma do leite de vacas: padrões e variabilidade. Dissertação de Doutorado em Clínica Veterinária, Faculdade de Medicina Veterinária e Zootecnia, Universidade de São Paulo, São Paulo, SP. $161 p$

Sant'Ana V.A.C., Birgel E.H., Rosenfeld A.M.F. \& Soares P.C. 2006. Proteinograma de vacas lactentes submetidas a retenção láctea. Braz. J. Vet. Res. Anim. Sci. 43(2):262-269.

Sawyer L. 2003. Beta-lactoglobulin, p.319-386. In: Fox P.F. \& McSweeney P.L.H. (Eds), Advanced Dairy Chemistry: protein. Vol.1. Kluwer Academic, Cork.

Schalm O.W. \& Noorlander D.O. 1957. Experiments and observations leading to development of the California Mastitis Test. J. Am. Vet. Med. Assoc. 130(5):199-204.

Silva J.B., Lopes C.T.A., Pinheiro C.P., Lima D.H.S., Silva R.S.L., Fonseca A.H., Araújo F.A. \& Barbosa-Neto J.D. 2013. Prevalência sorológica e molecular de Babesia bovis e Babesia bigemina em búfalos (Bubalus babalis) na Ilha de Marajó, Pará. Pesq. Vet. Bras. 33(7):847-850.

Triola M.F. 2008. Introdução à estatística. 10a ed. LTC, Rio de Janeiro. 696p. Voltolini T.V., Santos G.T., Zambom M.A., Ribas N.P., Muller E.E., Damasceno J.C., Ítavo L.C.V. \& Veiga D.R. 2001. Influência dos estádios de lactação sobre a contagem de células somáticas do leite de vacas da raça Holandesa e identificação de patógenos causadores de mastite no rebanho. Acta Scient. 23(4):961-966.

Zafalon L.F., Nader Filho A., Oliveira J.V. \& Resende F.D. 2005. Comportamento da condutividade elétrica e do conteúdo de cloretos do leite como métodos auxiliares de diagnóstico na mamite subclínica bovina. Pesq. Vet. Bras. 25(3):159-163. 